\title{
Research on the Impact of Information Network on Utilization Efficiency of Cultivated Land
}

\author{
JIANG Yanjun 1, a, HUANG Ying ${ }^{2, b}$ \\ 1, 2 Business School, University of Jinan, Shandong, China, 25000 \\ a1370707901@qq.com, b1935357670@qq.com
}

Keywords: Information network; Arable land; Utilization efficiency

Abstract: From the perspective of economy, society, and ecology, we study the impact of information networks on the utilization efficiency of cultivated land. Using the information entropy model evaluates the utilization efficiency of cultivated land from 2007 to 2016 in China, and empirically analyzes the the impact of information network on utilization efficiency of cultivated land. The conclusions: recent years, the utilization efficiency of cultivated land has been on the rise, but the overall level is low. The effect of information networks on the utilization efficiency of cultivated land is positive.

\section{Introduction}

Recent years, the problems of cultivated land reclamation have been prominent, and food security has been threatened in China ${ }^{[1]}$. Therefore, it is imperative to study the improvement of utilization efficiency for arable land. With the popularization of broadband networks and the development of the domestic economic, information networks affect the utilization of arable land to varying degrees and in distinct aspects. Combined with the Internet of Things, information networks effectively promote the purchase of farm tools, the inspection of land quality, negotiation of arable land circulation, and sales of agricultural products, shortening the agricultural production cycle, reducing the cost of agricultural production, and comprehensively increasing the efficiency of arable land utilization and farmers' income ${ }^{[2]}$. What's more, with the construction of agricultural platform of big data, the information network will achieve the accurate investment in various types of agricultural infrastructure, effective allocation and circulation of factors, and forecast of risks in agricultural production, improving the utilization efficiency of cultivated land in all aspects ${ }^{[3]}$. Therefore, from the perspective of economy, society and ecology, we study and empirically analyze the impact of information networks on the utilization efficiency of cultivated land.

\section{Influence mechanism of information network on comprehensive utilization benefit of cultivated land}

It is mainly from three aspects of economy, society, and ecology that the information network has effects on utilization of arable land, and influences the agricultural production cost and output efficiency, and then promotes the effective allocation of agricultural capital and the optimization of agricultural production structure.

From the perspective of economy, the effective utilization of arable land is mainly promoted in terms of agricultural production and sales. From the point of view of agricultural production, the information network has improved the efficiency of arable land utilization in terms of meteorological weather forecasting, farmland quality and nutritional demand detection, and modern 
production management. From the point of view of agricultural sales, people currently have a strong demand for green agricultural products, and consumers order agricultural products through online information, which promote the increase of agricultural producers' production of green agricultural products, expand the use of cultivated land, increasing the efficiency of arable land use, and promote the agricultural production chain effective cycle.

From the perspective of society, with the popularization of information networks, the construction and improvement of the agricultural platform of big data has been accelerated. The reform of the new round of the agricultural system has promoted the return of agricultural labor force. The rapid development of modern agricultural research and technology, and the transfer and scale of agricultural land has gradually become mainstream. The number of laborers going out decreasing, the pressure on employment in society being eased, the new-type professional farmers and modern agricultural infrastructure have also enhanced the effective use of cultivated land in China to a greater extent. At the same time, the quality of rural basic education has also gradually increased, providing potential human resources for agricultural production.

From the perspective of ecology, the use of information networks to strengthen the use of geographic information systems and various predictive models in agricultural production will protect the agricultural ecological environment from damage and effectively predict adverse climates, temperatures, and other harsh environments, enhancing the protection of green belts ahead of schedule, increasing the development of barren arable land, which make the most of the barren arable land reused, prevent soil erosion and re-desertification, meanwhile promote rural biological diversity and achieve sustainable development of agricultural green. With the background of modern information networks, the improvement of the utilization efficiency of cultivated land can bring about economic, social, and ecological development, making the country and farmers more likely to maintain the agricultural ecological environment, thereby improving the efficiency of the use of cultivated land and realizing the virtuous cycle of the development in green agriculture.

\section{Evaluation of utilization efficiency of cultivated land}

In this paper, comprehensive evaluation is conducted by selecting suitable indicators from different aspects, different perspectives, and multiple levels, and data-encoding information entropy models from 2007 to 2016 are used to evaluate the comprehensive benefits of China's arable land.

\section{The Selection of Evaluation Index}

We select several indicators from aspects of economy, society and ecology, etc. to evaluate the utilization efficiency of cultivated land in China. Specifically, the following indicators are included: (1) Indicators of economic efficiency represented by the per capita agricultural added value ( $\left.X_{1}\right)$ and the total mechanical power of the cultivated area per unit $\left(X_{2}\right)$. (2) Indicators of social benefits represented by the grain yield per unit of arable land $\left(X_{3}\right)$ and the rate of agricultural labor input ( $\left.\quad X_{4}\right)$. (3) Indicators of ecological benefits represented by the effective irrigated area $\left(X_{5}\right)$, stable yield index $\left(X_{6}\right)$, and multiple cropping index $\left(X_{7}\right)$ of the cultivated land per unit of land are used as. Steady production index=1-area affected by disasters/planting area, multiple crop index=planted area/total area of cultivated land, the input rate of agricultural labor=agricultural employed population/total employed population. 


\section{Positive Normalization of Indicators}

In order to make the research indicators consistent and the research results accurate, we normalized the indicators positively:

$$
x_{i j}=\frac{a_{i j}-a_{j}^{0}}{a_{j}^{*}-a_{j}^{0}}
$$

$a_{j}^{*}$ represents the largest number in this indicator, and $a_{j}^{0}$ represents the smallest

number, $\quad x_{i j}$ is between 0 and 1 .

\section{Comprehensive Evaluation}

To make the research result more accurate, we apply objective entropy method model to calculate the weight of each research indicator, and apply a simple linear weighted method to comprehensively evaluate the utilization efficiency for farmland in China.

Firstly, we need to determine the entropy weight of each research index. With Microsoft Excel,

we obtain the proportion

$$
k_{i j} \text { of each variable in the positive consistency evaluation matrix }
$$

$x_{i j}$ of each index:

$$
k_{i j}=\frac{x_{i j}}{\sum_{i=1}^{n} x_{i j}}
$$

Then we get the information entropy $\quad m_{i j}$ of each research variable from $k_{i j}$ :

$$
m_{\mathrm{j}}=-\frac{\sum_{i=1}^{n} k_{i j} \ln \left(k_{i j}\right)}{\ln (n)}
$$

With the value of information entropy we can calculate the coefficient of difference

each index:

$$
p_{j}=1-m_{j}
$$

Normalizing $\quad m_{j}$, the total weight of each indicator in research is 1 , and then the weight $\eta_{j}$ of each research indicator is obtained: 


$$
\eta_{j}=\frac{p_{j}}{\sum_{j=1}^{m} p_{j}}
$$

Finally, the comprehensive utilization benefits of cultivated land in China were evaluated using the data from 2007-2016 for various indicators. The results are shown in Table 1 as follows.

According to the analysis in Table 1, the utilization efficiency of cultivated land in China has generally increased year by year as a whole. However, the comprehensive scores are all below 0.51 , which indicates that the overall level is low.

Table 1 Utilization Efficiency Comprehensive Scores of Cultivated Land in China

\begin{tabular}{ccccccccc}
\hline Year & $X_{1}$ & $X_{2}$ & & & & & & Score \\
\hline Weight & 0.3487 & 0.2156 & 0.0494 & 0.2724 & 0.0207 & 0.0773 & 0.0159 & 1 \\
\hline 2007 & 0.0293 & 0.1357 & 0.0204 & 0.1111 & 0.0096 & 0.059 & 0.0138 & 0.3789 \\
\hline 2008 & 0.0309 & 0.1456 & 0.0215 & 0.1079 & 0.0099 & 0.0612 & 0.014 & 0.3909 \\
\hline 2009 & 0.0322 & 0.1393 & 0.0194 & 0.1038 & 0.009 & 0.0623 & 0.0128 & 0.3788 \\
\hline 2010 & 0.0337 & 0.1479 & 0.02 & 0.1 & 0.0092 & 0.0643 & 0.0129 & 0.3879 \\
\hline 2011 & 0.0353 & 0.1558 & 0.0209 & 0.0948 & 0.0094 & 0.0686 & 0.013 & 0.3978 \\
\hline 2012 & 0.037 & 0.1636 & 0.0216 & 0.0915 & 0.0095 & 0.0693 & 0.0131 & 0.4057 \\
\hline 2013 & 0.0387 & 0.1658 & 0.022 & 0.0855 & 0.0097 & 0.0674 & 0.0132 & 0.4023 \\
\hline 2014 & 0.0406 & 0.1725 & 0.0222 & 0.0804 & 0.0099 & 0.0686 & 0.0133 & 0.4074 \\
\hline 2015 & 0.0426 & 0.1784 & 0.0227 & 0.0771 & 0.0101 & 0.0689 & 0.0134 & 0.4132 \\
\hline 2016 & 0.1766 & 0.1736 & 0.0342 & 0.0216 & 0.0168 & 0.0624 & 0.1402 & 0.5021 \\
\hline
\end{tabular}

Empirical analysis of the effect of information network on the utilization efficiency of cultivated land

\section{The Selection of Variable and Data Sources}

To study the impact of information networks on China's arable land use efficiency, we select the number of Chinese websites (RIA) as the core independent variables. To reduce errors, rural household fixed assets investment (FAI), local fiscal farmland occupancy tax (LFL) and urbanization rate (PU) are selected as the independent variable indicating the impact of utilization efficiency of cultivated land, and the gross domestic product (GDP) is selected as the control variable. The integrated score (E) of comprehensive utilization efficiency of cultivated land obtained in the previous part is taken as the model's interpreted variable, and the data of 2007-2016 are selected as the annual data of the main impact indicators. The raw data comes from China Statistical Yearbook, etc.

\section{Model Establishment}

In order to reduce the influence of errors caused by data fluctuations, the indicators are taken as logarithms to establish the following measurement model:

$$
\ln \mathrm{E}=\alpha_{i}+\beta_{1} \ln R I A+\beta_{2} \ln F A I+\beta_{3} \ln L F L+\beta_{4} \ln P U+\beta_{5} \ln G D P+\gamma_{i}
$$

where ${ }^{\alpha_{i}}$ is the intercept term and ${ }^{\gamma_{i}}$ is the disturbance term. 


\section{Model Solution and Empirical Analysis}

Using Stata12 for regression analysis, the results are as Table 2. the analysis shows that the correlation coefficient between the information network and the comprehensive score is only 0.019581. The impact of the information network on the utilization efficiency of cultivated land in China is positive, but not significant. Investigating the reason, currently, the mobility of labor force in China is large, especially the transfer of rural labor forces to cities and towns, which has led to slow development and insufficient utilization of infrastructure such as rural information networks. In addition, the program of agricultural big data in China is under construction and cannot effectively promote the efficient utilization and management of arable land. China's land vast, and regional differences complex, the use and management of information networks has become more difficult, resulting that the information network have little effect on the use of cultivated land.

Table 2 Model regression results

\begin{tabular}{ccccc}
\hline & Coef. & Std. Err. & $\mathrm{t}$ & $\mathrm{p}$ \\
\hline RIA & 0.019581 & 0.191234 & 0.1 & 0.923 \\
\hline FAI & 1.943543 & 2.727798 & 0.71 & 0.516 \\
\hline LFL & 0.121424 & 0.892783 & 0.01 & 0.99 \\
\hline PU & 2.851487 & 6.026703 & 0.47 & 0.661 \\
\hline GDP & -1.052009 & 0.898881 & -1.17 & 0.307 \\
\hline cons & -0.7653611 & 13.35789 & -0.06 & 0.957 \\
\hline R-squared & 0.629 \\
\hline Adj R-squared & 0.1652 \\
\hline
\end{tabular}

\section{Conclusions and Recommendations}

\section{Conclusion}

In the past 10 years, the utilization efficiency of cultivated land in China has continuously improved, but the overall level is low. The network and information can promote the improvement of the utilization efficiency of cultivated land, but the effect is not significant. The occupation tax of cultivated land, rural household investment in fixed assets and urbanization can all promote the effective use of cultivated land, and the correlations are larger than those of information networks, but they are not significant, either.

\section{Recommendations}

In order to improve the utilization efficiency of cultivated land in China, the following suggestions are as follows: 1. Strengthen rural network construction and maintain rural network security. 2. Implement cooperation plans between scientific research in universities and local agricultural production, directly promoting the effective use of cultivated land. 3. Implement a preferential subsidy policy for agricultural production. 4. Prevent excessive use of pesticides and fertilizers to improve soil quality. 5. Actively introduce talents and advanced agricultural technologies of production. 6. Strengthen the construction of agricultural infrastructure.

\section{References}

[1] Zhao Yanfeng, Zhang Huanan, Cheng Daoquan et al. Soil Fertility Evaluation of Provincial Provinces Based on Merged "Soil Configuration" Map[J]. Soil Bulletin, 2015, 46(5): 1040-1048. 
[2] Dumanski J, Desjardins R L, Tarnocai C, et al. Possibilities for Future Carbon Sequestration in Canadian Agriculture in Relation to Land Use Changes[J]. Climatic Change, 1998, 40(1):81-103.

[3] Xin L I, Ming-Hao O U, Xian-Lei M A. Analysis on Impact of Fragmentation Based on Landscape Index to Cultivated Land Use Efficiency-A Case on Lixiahe District in Yangzhou City[J]. Journal of Natural Resources, 2011. 